\title{
Meeting Report and Special Issue Preface: The 54th Seminar of the Korean Society of Gastrointestinal Endoscopy
}

\author{
Won Jae Yoon ${ }^{1}$ and Jong Kyun Lee ${ }^{2}$ \\ ${ }^{1}$ Department of Internal Medicine, Inje University Seoul Paik Hospital, Inje University College of Medicine, Seoul, ${ }^{2}$ Department of Medicine, \\ Samsung Medical Center, Sungkyunkwan University School of Medicine, Seoul, Korea
}

The Korean Society of Gastrointestinal Endoscopy (KSGE) has been hosting seminars since 1989. The seminars have contributed much to the spread of knowledge about gastrointestinal (GI) endoscopy. Indeed, the seminars of the KSGE have become among the most attended educational seminars held in Korea.

The 54th seminar was held on March 20th, 2016. The number of participants was over 3,800, reflecting great interest in the medical community. The program consisted of more than 20 sessions with 80 lectures and case discussions. The didactic lecture sessions covered basic and advanced knowledge on upper and lower GI endoscopy, endoscopic retrograde cholangiopancreatography (ERCP), and endoscopic ultrasonography. In addition, topics of discussion included endoscopic quality improvement programs, sedation for endoscopy, disinfection of endoscopes, and infection control in endoscopy suites. A dedicated session for GI endoscopy nursing was also held. The live demonstration sessions shared important tips for upper and lower GI endoscopy. Finally, the colonoscopy hands-on course and disinfection course provided valuable learning experience. The contents of the seminar can be accessed through the KSGE website (http://www.gie.or.kr/).

The editorial committee of the KSGE carefully selected and invited 12 lectures from the 54th seminar to be published in this issue. The topics include gastric cancer, management of foreign bodies in the GI tract, colorectal polyps, inflammatory bowel disease, ERCP, and a national endoscopic quality improvement program. We hope and believe that this issue of Clinical Endoscopy will provide the readership with the highlights of the core contents of the seminar.

\section{Conflicts of Interest}

The authors have no financial conflicts of interest.
Received: May 27, 2016

Correspondence: Jong Kyun Lee

Department of Medicine, Samsung Medical Center, Sungkyunkwan University School of Medicine, 81 Irwon-ro, Gangnam-gu, Seoul 06351, Korea

Tel: +82-2-3410-3410, Fax: +82-2-3410-6983, E-mail: jongkyunlee@gmail.com

(c) This is an Open Access article distributed under the terms of the Creative Commons Attribution Non-Commercial License (http://creativecommons.org/ licenses/by-nc/3.0) which permits unrestricted non-commercial use, distribution, and reproduction in any medium, provided the original work is properly cited. 